\title{
PUBLIC RELATIONS ETHICS IN INFORMATION MANAGEMENT
}

\author{
Hrvoje Jakopović \\ hrvoje.jakopovic@fpzg.hr \\ University of Zagreb, Croatia
}

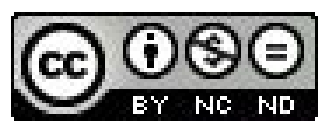

\begin{abstract}
Public relations is involved in all communication between an organization and the public. In the contemporary world, PR practitioners have become the facilitators of information. Information and communication technology (ICT) have imposed new rules in the field of public relations. Communication strategy and information management have become crucial parts of modern public relations. People change their habits with regard to the consumption of traditional and new media. The challenges imposed by the development of information and communication technology are also related to understanding the new information society. For that reason information ethics deals with the ethical implications of dissemination, use, development and safety of information. Public relations follow new information and communication trends, and they need to build firm ethical principles for the age of information. The author examines the ethical implications of the framing concept in public relations.
\end{abstract}

Key words: public relations, information society, information ethics, information and communication technology, information science, framing.

\section{THE DEVELOPMENT OF INFORMATION SOCIETY}

Many things in the world have changed since the time when the first electronic computers were invented in the twentieth century. The impact of information technology on peoples' lives is huge and today we are witnesses of a changing environment in which our society redefines itself in various ways, especially in one aspect that pervades every part of the human community and that is communication. With it we transfer messages, information and knowledge. The communication process is differently and widely understood because of its complexity. George A. Theodorson and Achilles G. Theodorson define communication as "the transmission of information, ideas, attitudes, or emotion from one person or group to another (or others) primarily through symbols" (Theodorson \& Theodorson, 1992, cited in Theaker, 2001, p. 13). Some authors see it in the way of "exchange of messages through some channel and in some medium" (Danesi, 2009, p. 69). Many public relations theoreticians (Broom, 2010; Tench \& Yeomans, 2009; Theaker, 2001) use the simple models of communication such as Shannon's model (1948) as the starting point for explaining the process. This model of communication was published in A Mathematical Theory of Communication. The model set out by Claude E. Shannon (1948) consists of an information source, signal, transmitter, channel, noise, receiver and destination as parts of the communication process. Alison Theaker (2001) 
pointed out that it was important because it imposed the concept of interference in communication. Interference is observed as noise during the transmission of a message sent from an information source to a receiver and a destination. In that process the message can become distorted and obtain a different meaning for the person who receives it. This explanation of communication is still a useful ground theory which which needs upgrading in light of the unpredicted development of information technology.

Already more than a half of century has passed since the time when the first idea and concept of a new society was mentioned. In his paper The Production and Distribution of Knowledge in the United States Fritz Machlup (1962) used a concept of "knowledge industry". At the beginning of the new century, "information society" became a term which relates to a new environment and form of society. The specifics of this new society are widely interpreted. Manuel Castells (2010) has a different view on the terms of "information society" and "informational society". For M. Castells (2010), information society underlines the importance of information in society. On the other hand, informational society "indicates the attribute of a specific form of social organization in which information generation, processing, and transmission become the fundamental sources of productivity and power because of new technological conditions emerging in this historical period" (Castells, 2010, p. 21). M. Castells (2010) also proposes the term "network society", because it indicates a form of networking in social organization and social practice. Other authors, such as Divina Frau-Meigs (2006), point out that the term "information society" can be insufficient as a notion for this complexity and proposes other solutions:

Social sciences are also critical of buzzwords and they have cast doubts about the phrase »Information Society«. The civil society document reflects this careful weighing of the meaning of the words, by systematically replacing Information by Knowledge, by associating Information with Communication, by adding an »s" to Society, thus acknowledging the diversity of cultures (Frau-Meigs, 2006, p. 85).

One of the specifics that were noticed in the growth of information society is Paul Nihoul's (2005) observation that it is moving away from concentration towards decentralization. From one perspective this is manifested by the increased access to information, different media and user generated content $\left(\mathrm{UGC}^{3}\right)$. Audiences are no longer the passive recepeints of media content, but the active searchers and the creators of content in accordance with their needs. Paul Verschueren (2006) also interpreted that concept through distinction between newer online realities and older offline realities. The technological insight provides another point of view into the concept: "The key idea is that breakthroughs in information processing, storage and transmission have led to the application of information technologies (IT) in virtually all corners of society" (Webster, 2005, p. 7). This technological perspective is firmly supported by the fact that "the number of Internet users on the planet grew from under 40 million in 1995 to about 1.5 billion in 2009" (Castells, 2010, p. xxv). These indicators show how our communication and relationships have changed.

Public service broadcasting corporations, such as British Broadcasting Corporation, interpret user generated content (UGC) "as »citizen journalism«, »social media" or "participatory media «" which "refers to a wide variety of media content that is produced by our audiences as opposed to content made by the BBC, independent production companies or individual contributors commissioned by BBC". Retrieved December 12, 2012 from http://www.bbc.co.uk/terms/faq.shtml. 
The term that additionally emphasizes this is the notion of "web 2.0", which Tim O'Reilly brought up in 2003. According to the interpretation of David Phillips and Philip Young (2009) "the evolution of the web from a repository of information and communication technologies into a space for symmetrical communication: a platform that aids the transfer of knowledge and conversations and a place where people can easily mix and match both" (Philips \& Young, 2009, p. 103). It is clear that by using social networks, such as Facebook, Twitter, LinkedIn, Google+ and Skype, we communicate without any spatial boundaries. We can simultaneously include numerous persons in our online conversations. As a modern concept, "Information and Communication Technology (ICT)" has in many ways replaced the term "IT" (Information Technology), because it emphasizes the use of communication through converged media. According to Howard Rheingold (1993, cited in Staes, 2006), these recent information and communication technologies should be applied in several ways: for encouraging citizens to participate in politics and active power, for interacting with various individuals, and for creating new vocabularies and new types of communication. The question of the digital divide still remains open and represents a challenge for information society. The implementation of ICT is important for solving this problem which is present because many people around the world do not have a computer or an access to information. The European Consortium for Communications Research (ECCR, 2006) deems that a mature and desirable information society depends on providing ICT access to those who are underprivileged. It is also important to educate users, and give them skills and abilities for effective and responsible use of information and communication technology (ECCR 2006). This implies finding and retrieving information which is relevant to users and creating a usergenerated content. ECCR (2006) recognizes that in a form of Internet governance "Information Society cannot be left to the law of the strongest, nor can it be regulated by particular interests, be they of a nation or an industry" (p. 207).

Currently, we perceive that ICT is changing the professional and private lives of many people. Luc Soete (1997, cited in Servaes \& Carpentier, 2006) claims that the information society is put in place which is characterized by the common use of low-cost information, data storage and transmission technologies. It is hard to imagine a job today that, in a certain aspect, does not need some form of ICT. This is particularly true for those professions such as public relations, which are focused on establishing quality relationships. It is a relationship between a client, which can be an organization or an individual, and their public. Public Relations (PR) relies on communication and observes communication trends for maximizing the effects of their programs. For this reason, it is not uncommon that the first specialized PR agencies which dealt with ICT industry (Tench \& Yeomans, 2009) emerged as early as in the 1990s and the early 2000s. Public relations deal with the public, which, in short, forms our society. For PR, it is not only important to identify who are the members of the public but also what the characteristics of contemporary communication are at the society level.

\section{NEED FOR INFORMATION ETHICS}

Information ethics is frequently observed as a discipline that evolved from information science which we can perceive as a young science that "routinely interacts 
with and draws liberally upon other subject fields for intellectual enrichment" (Cronin, 2008, p. 466). It is often described as an interdisciplinary science which relates to information technology, communication science and information retrieval. According to Mehdi Khosrow-Pour (2009), information science is deeply integrated in medicine, learning, finance, government, and numerous other areas. Information ethics has found ground in the concept of information society, which is looking for solutions for many ethical problems that arise from its complexity. Luciano Floridi (2001, cited in Partridge, 2005) observes the digital divide as a source of these problems. It is the role of information ethics to set the norms of moral acts in relation to those conditions. The digital divide "can engender new forms of colonialism and apartheid that must be prevented" (Floridi, 2001, cited in Partridge, 2005, p. 29). The question of access to information raises dilemmas for our society and for many professions which are dealing with information exchange. That includes the profession of public relations providers because of their role to serve the client, but also the public and, in some aspects, to serve public interest. If this is the "age of information" 4 and we live in an information society, those who do not have access to information are effectively excommunicated from society. They cannot participate in society and be informed about things that concern them. The inclusion in society is conditioned by the possession of ICT and information literacy. At the World Summit on the Information Society, the Minister of Transport and Communications of the Republic of Turkey, Binali Yildirimat, stated the following:

Freedom as access to information and knowledge is the cornerstone in transforming the world into an Information Society. As a prerequisite for the democratic societies governed by the rule of law, the right to access to information and knowledge should be included among the fundamental rights and freedoms and be defined as such at constitutional level (State Planning Organization [SPO], 2004, cited in Christensen, 2006, p. 142).

We can also understand the issues which are relevant for information ethics through a term of "infosphere". This term coined by L. Floridi (2008) encompasses the whole informational environment formed by all informational entities: informational agents, properties, interactions, processes, and mutual relations. Infosphere is a parallel environment which includes offline and analogue spaces of information (Floridi, 2008). It is constructed from many different elements which are mutually intertwined and cannot be observed independently. Infosphere describes a space within which information society is organized. Rafael Capurro (2006) deems that information ethics refers to questions of the intersection of the infosphere, which is formed of ecological, political, economic, and cultural spheres. These questions by R. Capurro (2006) are focused on the Internet, which is changing local cultural values and traditional ways of life, effects of these changes on the life and culture of future societies in a global and local sense and, finally, on transformation of traditional cultures and their moral values under the impact of the digital infosphere in general and of the Internet specifically. We also witness intercultural changes with the conversions of particular traditional cultures and their values. These changes are obvious in communication. We are a part of

Castells (2010) sees digital networking technologies characteristic for the Information Age which is specific because it allows endless expansion and reconfiguration of social and organizational networks. 
the globalized world in which information can freely flow from one continent to another. The consequences of these processes are observed in the overflow and merging of different cultures. Kanishka Jayasuriya deems that "globalization is reshaping the fixed and firm boundary between domestic and international spheres and changing our conceptions of the proper domain of domestic and international politics and law" (Jayasuriya, 1999, cited in Marsden, 2005, p. 20). Rafael Capurro understands and emphasizes the role of Intercultural Information Ethics and points out that "in a narrow sense it focuses on the impact of information and communication technology (ICT) on different cultures as well as on how specific issues are understood from different cultural traditions." (Capurro, 2008, p. 639). In general, information ethics needs to be applied in many different ways.

Surely, information ethics has an important role in information management. In $\mathrm{PR}$, it is important to reconsider how to use information in the contemporary world. What are the implications of old practices in terms of using information and how they could be reinforced with some new ideas? Today, the concept of information is viewed in a different way than in the past, because we are exposed to a wide range of information. Some of this information, which we create within the Internet space, became the focus for various market researchers. Castells (2009) noticed that, with the development of ICT, workers became increasingly dependent on computer networking in their activity and most companies have decided that they are entitled to monitor them when they are online. At first, with the beginning of the Internet, it seemed that we could protect our privacy. That nation was based on the concept of anonymity. It was possible to introduce oneself by a nickname and it seemed as though we could not be identified. Today, the situation is different, so public relations campaigns by Ralph Tench and Liz Yeomans (2009) should set educating individuals and organizations as one of their goals in the terms of need to adopt proactive practices and protect their own data.

\section{PUBLIC RELATIONS AND USE OF INFORMATION}

In information science, "information" is seen as a complex phenomenon which has various physical, biological and social properties (Tuđman, Boras \& Dovedan, 1992). In order to be able to comprehend in which way public relations use information, it is necessary to define the profession. There are numerous interpretations of the PR function, and all of them have something in common. That is the notion of "communication" as a crucial part of the profession. One of the shortest definitions is that public relations make "communication with various areas the public" (Kitchen, 1997, cited in Tench \& Yeomans, 2009, p. 5). As it was mentioned before, communication, is a very complex notion which many authors define in terms of message transmission. Those messages are actually made up of different symbols (Kunczik \& Zipfel, 2006; Reardon, 1998; Tuđman et al., 1992). Symbols can be various: words, gestures, sound or visual displays. There is also the concept that an individual per se represents a kind of message. That is to say that the meaning is not in words, but in humans (Broom, 2010). We can also give different meanings to the received information and, because of that, it is necessary for PR practitioners to 
identify and be given insights into the opinions and attitudes of their public. David C. Leege and Kenneth D. Wald (2007) specifically interpret meanings as follows:

Meaning is "an attribute of symbolism" and is a function of the context in which the symbol or the individual himself, was located. (...) They are found in pictures and sounds that tap into primary group experiences of things that promote pride or satisfaction or tap into reservoirs of fear or revulsion... Meaning is invested with emotion. It is far distant from cool rationality (Leege \& Wald, 2007, cited in Castells, 2009, p. 191).

Carl H. Botan and Maureen Taylor (2004) assert that "differences in how the relationship between the public and issues is understood are central to understanding how applied communication works - or does not work" (p. 654). These concepts provide another view of our relationships and communication. This idea cannot be disregarded and can be helpful for the development of public relations in a new direction. Not only that information which PR practitioners send should be in time, but it should also be placed in the proper social context. Messages can be empowered and have a stronger effect on the public considering these aspects. The use of information in PR also includes knowledge about the medium used for sending messages. Every medium has its own characteristics. Traditional media, such as television, radio and press, are often used for informing the broader audience. We cannot expect to establish such a direct communication with the public as is possible through social networks. Many authors emphasize that the crucial advantage of social media is the possibility of establishing direct communication with individuals (Brown, 2009; Phillips \& Young, 2009; Scott, 2007; Solis \& Breakenridge, 2009).

For some PR experts communication has several functions. Glen M. Broom (2010) perceives it as a process of mutual exchange of a signal with the goals of informing, persuasion and teaching. The ethical dilemma arises from the sense of using persuasion in public relations. Feminist theorist Sally M. Gearhart sees persuasion as an "act of violence" (Bivins, 2004). From that perspective persuasion leads to the imposition of specific ideas. On the other hand, persuasion is defined as "a symbolic process in which communicators try to convince other people to change their attitudes or behavior regarding an issue through the transmission of a message, in an atmosphere of free choice" (Perloff, 2006, cited in Tench \& Yeomans, 2009, p. 256). This view highlights the fact that the person who is persuaded has the freedom of choice to accept or not to accept the received information. This persuasive approach is based on arguments and rhetoric, and should not be confused with propaganda. One of the reasons why propaganda is often put in a negative context is because it uses half-truths to shape the perception. It is defined as "deliberate and systematic attempt to shape perceptions, manipulate cognitions and direct behaviour to achieve a response that furthers the desired intent of the propagandist" (Jowett \& O'Donnell, 1992, cited in Tench \& Yeomans, 2009, p. 256).

We can argue that public relations are not absolutely impartial because they are hired by the client (organization) and so it is their task to service them. But what is recognized as crucial in their activity is the authenticity of provided information. Not only is lying is unethical for a PR practitioner, but it can also do harm to the client. The accuracy of information can be examined through the activities of the client that PR represents. The information transmitted to the public needs to be in accordance with 
the organization's actions. Shannon A. Bowen (2004) deems that issue managers (i.e. PR managers) should integrate business decisions with ethics. The question is to what extent are PR practitioners aware of applied ethics in their work. S. A. Bowen (2008) conducted research on the role of ethics in public relations practice. The PR experts examined were asked these questions: " 1 . Do public relations professionals believe that they should act as the ethical conscience of the organization?, 2. To what extent, if any, do public relations professionals counsel the dominant coalition or CEO on matters of ethics?" (Bowen 2008, p. 277). Key findings show that those PR experts who had antiethical atittudes stated that ethics is not important in business, because they follow legal regulations, but do not advise CEOs (Chief Executive Officer) on ethics because of their role to advocate (Bowen, 2008). On the other hand, according to Bowen (2008), one group of the examinees asserted that organization reputation and ethics are natural partners, the essence of ethical thinking comes from responsibility to the public and that today it is becoming more common to act as a conscience of the organization.

This new perspective leads to the concept of public relations as an open system, which was suggested by Scott M. Cutlip, Allen H. Center and Glen M. Broom (2000). The idea is based on systems theory which is very often mentioned in various literature on public relations (Broom, 2010; Kunczik, 2006; Theaker, 2001). Public relations as a system can be explained through units of the public and organizations which are in interaction inside flexible boundaries and have a mutual affect. PR as an open system implies the idea of organization's reacting to the feedback that is coming from environment and, in accordance to it, changes its activities. The notion is clear in M. Cutlip's definition of public relations: "public relations is the management function that establishes and maintains mutually beneficial relationships between an organization and the public on whom its success or failure depends" (Cutlip et al., 2000, p. 6). To achieve that kind of relationship, it is necessary to take into consideration James Grunig and Todd Hunt's "two-way symmetrical model" (1984; Tench \& Yeomans 2009), which enables free flow of information in which receivers and senders hold equal positions. On an everyday basis, this kind of information exchange can be found in dialogue with other people.

\section{ETHICAL IMPLICATIONS OF THE "FRAMING" CONCEPT}

It has long been established that individuals cannot absolutely understand the world they live in. They are actually constantly fighting with the interpretations of their realities. The great volume of information which surrounds them in the information society brings even more confusion. The human mind has found a solution for that problem and uses a kind of mental map which enables easier information processing and information organization. The concept of "framing" deals with these processes. A sociologist Erving Goffman (1974) set up the grounds. The grounds for the theory in his paper Frame analysis: An essay on the organization of experience. E. Goffman (1974) observed "primary frameworks" as the ones that individuals use for the classification and meaningful interpretation of information. The concept is used in many different fields of science. Among those, there are also disciplines such as psychology, sociology and communication sciences. Robert M. Entman (2004, cited in Castells, 2009) observes framing as the process of "selecting and highlighting some facets of events or issues, and making connections 
among them so as to promote a particular interpretation, evaluation and/or solution." (R. M. Entman, 2004, cited in Castells, 2009, p. 158). If that is the idea, some parts of the experienced event will be emphasized and the other parts put aside. M. Castells deems that "the mechanisms of information processing that relate the content and format of the message to the frames (patterns of neural networks) existing in the mind are activated by messages generated in the realm of communication." (2009, p. 155).

Many people agree that the media has an important role in building frames. Claes H. de Vreese (2005) sees several stages of framing information in media: frame-building, frame-setting and consequences of framing on the individual and social level. According to C. H. de Vreese (2005), frame-building is occurring in the newsrooms and includes internal factors, such as editorial policies, and new values, as well as external factors such as various interest groups (e.g. public relations). Framing in the news also consists of forming issue-specific and generic frames (de Vreese, 2005) which leads to frame-setting. De Vreese (2005) understands the framing effects through changes in information processing, attitudes and behavior of audiences. Similar is the vision of Dietram A. Scheufele (1999), who distinguishes "media frames" and "individual frames". Individual frames are those which we form through non mediated cognition, as opposed to media frames which are formed by other individuals such as news editors and journalists.

It seems that there is not enough debate about the applicability and ethics of framing concept in public relations. Some of the authors in the area of public relations conducted research based on the framing concept (Froehlich \& Rúdiger, 2006) but it seems there is a still room for further development. In his paper Seven Models of Framing: Implications for Public Relations, Kirk Hallahan (1999) stressed seven elements that can be framed in public relations: 1. Situations, 2. Attributes, 3. Choices, 4. Actions, 5. Issues, 6. Responsibility, 7. News. His idea of situation framing is based on the principles described by E. Goffman. We can comprehend the framing of attributes by pointing out some characteristics of organization that public relations use for forming a positive image. The model of attributes goes with concept of framing choices which assumes that individuals are ready to make risky decisions when they have something to lose, but not if they can have benefit. People's actions are connected and triggered by emphasizing the negative consequences of unwanted acts (Hallahan, 1999). For the issues which represent some sort of issue and are differently interpreted, public relations among all have an obligation, that we can see as ethical, to shape the common perspective and agreement between different public spheres. The ethical dilemma in framing responsibilities in PR concerns the notions of accepting guilt or shifting the blame. Finally, the concept of news framing was already mentioned and leads us to the core values of news that are used in journalism. Therefore, public relations in information management needs to obtain an insight into journalistic practice. The crucial question for public relations in the process of framing information is whether or not their activities allow free flow of information. The Public Relations Society of America Member Code of Ethics (Public Relations Society of America [PRSA], 2000) implies the use of accurate and truthful information which serves the public interest. PR professionals need to have in mind that they cannot use framing in such a manner as to give a completely wrong or false image of their client. PRSA Code of Ethics (2000) also emphasizes this ethical question of published information with the term "lying by omission". 


\section{THE ROLE OF PUBLIC RELATIONS IN THE INFORMATION SOCIETY}

Various professions are currently in the situation of redefining their roles, including public relations. The reasons for this are changes manifested, above all, in the way we communicate with each other, and the way we use and select information. Those circumstances are nearly described in the term of "information society" which encompasses many ethical issues. These issues are primarily of all related to the digital divide and privacy when using the Internet. Information ethics deals with those issues as a discipline which arose from information science and the notion of information society. We can see that there is one component which connects the information science, information society and information ethics and that is information and communication technology (ICT). From that perspective, technology should be seen as a key driver of development or a change in society. The expansion of technology at an incredible speed appears almost out of control. That is why information society is very differently defined and provokes other expressions such as "network society", "knowledge society" or a concept of many societies in an information age.

This new environment, which is constantly changing for public relations, means that it is crucial to have the skills for a swift adjustment of communication. PR practitioners are now facilitators of information, and it gives them more power - but also more responsibilities toward the public. The public relations profession now has a role in information management. This position of power indicates that the ethical issues surpass the basic target public and, therefore, raises the question of acting in the public good. Concepts such as framing theory are becoming potentially very useful with this new empowered role of public relations in governing information. Public relations practitioners can enrich the raw information and thus give it a certain meaning, which intertacts with emotions of the individual. In brief, the power of communication can be observed as the power of influence on people's emotions. In this respect, public relations need to put the interest of the public before any other interests in order to be able to create an environment of trust in the suspicious society of information.

\section{REFERENCES}

Bivins, T. H. (2004). Mixed Media: Moral Distinctions in Advertising, Public Relations and Journalism. New Jersey London: Lawrence Erlbaum Associates.

Botan, C. H., Taylor, M. (2004). Public Relations: State of the Field. Journal of Communication, 54(4), 645-661.

Bowen, S. A. (2008). A State of Neglect: Public Relations as "Corporate Conscience" or Ethics Counsel. Journal of Public Relations Research, 20, 271-296.

Bowen, S. A. (2006). Expansion of Ethics as the Tenth Generic Principle of Public Relations excellence: A Kantian Theory and Model for Managing Ethical Issues. Journal of Public Relations Research, 16 (1), 65-92.

Broom, G. M. (2010). Cutlip and Center's Effective Public Relations. Zagreb: Mate.

Brown, R. (2011). Public Relations and the Social Web: How to use social media and web 2.0 in communications. London - Philadelphia: Kogan Page.

Castells, M. (2010). The Rise of the Network Society. New Jersey: Wiley - Blackwell.

Castells, M. (2009). Communication Power. New York: Oxford University Press.

Capurro, R. (2008). Intercultural Information Ethics. In: K. Einar Himma, H. T. Tavani (eds.). The Handbook of Information and Computer Ethics. New Jersey: John Wiley \& Sons, Inc., Hoboken.

Capurro, R. (2006). Towards An Ontological Foundation of Information Ethics. Ethics and Information Technology, 8 (4), 175-186. 
Christensen, M. (2006). What Price the Information Society? A Candidate Country Perspective within the Context of the EU's Information Society Policies. In: J. Servaes, N. Carpentier (eds.). Towards a Sustainable Information Society. Bristol - Portland: Intellect.

Cronin, B. (2008). The sociological turn in information science. Journal of Information Science, 34 (4), 465-475.

Danesi, M. (2009). Dictionary of Media and Communications. New York - London: M.E. Sharpe.

de Vreese, C. H. (2005). News framing: Theory and typology. Information Design Journal, 13 (1), 51-62.

Einar Himma, K., Tavani, H. T. (eds.). The Handbook of Information and Computer Ethics. New Jersey: John Wiley \& Sons, Inc., Hoboken.

European Consortium for Communications Research (2006). Recommendations on the Subject of Research and Education in the Area of the Information Society. In: J. Servaes, N. Carpentier (eds.). Towards a Sustainable Information Society. Bristol - Portland: Intellect.

Floridi, L. (2008). Foundations of Information Ethics. In: K. Einar Himma, H. T. Tavani (eds.). The Handbook of Information and Computer Ethics. New Jersey: John Wiley \& Sons, Inc., Hoboken.

Frau-Meigs, D. (2006). Civil Society's Involvement in the WSIS Process: Drafting the Alter-Agenda. In: J. Servaes, N. Carpentier (eds.). Towards a Sustainable Information Society. Bristol - Portland: Intellect.

Froehlich, R., Rúdiger, B. (2006). Framing political public relations: Measuring success of political communication strategies in Germany. Public Relations Review, 32, 18-25.

Goffman, E. (1974). Frame analysis: An essay on the organization of experience. Boston: Northeastern University Press.

Hallahan, K. (1999). Seven Models of Framing: Implications for Public Relations. Journal of Public Relations Research, 11 (3), 205-242.

Khosrow-Pour, M. (ed.) (2009). Encyclopedia of Information Science and Technology. Hershey - New York: Information Science Reference.

Kunczik, M. (2006). Public Relations: Concepts and Theories. Zagreb: Faculty of Political Science.

Kunczik, M., Zipfel, A. (2006). Uvod u znanost o medijima i komunikologiju [Introduction to Science of Media and Communication]. Zagreb: Zaklada Friedrich Ebert.

Machlup, F. (1962). The Production and Distribution of Knowledge in the United States. Princeton: Princeton University Press.

Marsden, C. T. (ed.). Regulating the Global Information Society. London - New York: Routledge.

Nihoul, P. (2005). Will electronic commerce change the law? Towards a regulatory perspective based on competition, information and learning skills. In: C. T. Marsden (ed.). Regulating the Global Information Society. London - New York: Routledge.

Patridge, H. (2005). Establishing the Human Dimension of the Digital Divide. In: M. Quigley (ed.). Information Security and Ethics: Social and Organizational Issues. Hershey, London, Melbourne, Singapore: IRM Press.

Phillips, D., Young P. (2009). Online Public Relations. London - Philadelphia: Kogan Page Limited.

Public Relations Society of America (2000). Public Relations Society of America Member Code of Ethics. Retrieved from http://www.prsa.org/AboutPRSA/Ethics/CodeEnglish.

Quigley, M. (ed.). Information Security and Ethics: Social and Organizational Issues. Hershey, London, Melbourne, Singapore: IRM Press.

Reardon, K. K. (1998). Interpersonal Communication. Zagreb: Alinea.

Scheufele, A. D. (1999). Framing as Theory of Media Effects. Journal of Communication, 49(1), 103-122.

Scott, M. (2007). The New Rules of Marketing and PR. New Jersey: Wiley.

Servaes, J., Carpentier, N. (2006). Introduction: Steps to Achieve a Sustainable Information Society. In: J. Servaes, N. Carpentier (eds.). Towards a Sustainable Information Society. Bristol - Portland: Intellect.

Servaes, J., Carpentier, N. (eds.) (2006). Towards a Sustainable Information Society. Bristol - Portland: Intellect.

Shannon, C. E. (1948). A Mathematical Theory of Communication. The Bell System Technical Journal, 27, $379-423$.

Solis, B., Breakenridge, D. (2009). Putting the Public Back in Public Relations. New Jersey: Pearson Education, Inc.

Staes, B. (2006). Foreword: Towards a New Democratic Lingua Franca: Opening Speech at the ECCR WSIS conference, European Parliament March 1, 2004. In: J. Servaes, N. Carpentier (eds.). Towards a Sustainable Information Society. Bristol - Portland: Intellect.

Tench, R., Yeomans, L. (2009). Exploring Public Relations. Harlow: Pearson Education Limited.

Theaker, A. (2001). The Public Relations Handbook. London - New York: Routledge.

Tuđman, M., Boras, D., Dovedan, Z. (1992). Uvod u informacijsku znanost [Introduction to Information Science]. Zagreb: Školska knjiga.

Verschueren, P. (2006). From Virtual to Everyday Life. In: J. Servaes, N. Carpentier (eds.). Towards a Sustainable Information Society. Bristol - Portland: Intellect.

Webster, F. (2005). Theories of the Information Society. London - New York: Routledge. 